\title{
EL TEATRO DE SALA Y ALCOBA EN LA CATALUÑA DEL SIGLO XVIII: UN ACTO SOCIAL EN UN ESPACIO PRIVADO E ÍNTIMO ${ }^{1}$
}

\author{
NÚRIA RUIZ COMÍN \\ Asociación para el Estudio del Mueble
}

Fecha de recepción: enero 2012

Fecha de aceptación: febrero 2012

Las representaciones teatrales privadas eran un tipo de diversión que practicaban todas las capas sociales, aunque en este artículo nos centraremos en la sociedad barcelonesa y una cronología que abarca desde mediados del siglo XVIII hasta el primer tercio del siglo XIX. Estas representaciones fomentaban las relaciones sociales y para su puesta en escena utilizaban diferentes espacios, bien locales alquilados para tal fin, bien las propias dependencias de la casa de quienes las organizaban, incluidas las más íntimas, como son las salas y alcobas. El dormitorio se convertía por lo tanto en un espacio de ocio, en un teatro, donde la alcoba hacía las veces de escenario y la sala de platea.

Teniendo en cuenta las diferencias de recursos económicos entre las clases sociales y sus diferentes posibilidades materiales, las representaciones particulares se desarrollaban de distinta forma y condiciones. En el caso de las clases altas eran la excusa para mostrar el estatus social y económico de quien las organizaba. Hacían público el evento, anunciando los ensayos en el diario local (Diario de Barcelona) o mediante invitación personal. Esta última además, otorgaba categoría al acto y a los invitados, ya que diferenciaba su rango y según éste, los distribuía en las diferentes sesiones. Las funciones se celebraban en los lujosos interiores de sus casas, decorados con los

\footnotetext{
1. Este artículo recoge parte de mi trabajo: «Els Teatres Particulars a Barcelona en el Segle XVIII». El teatre representat en els espais domèstics. Correspondiente a la tesina del Máster: Estudis Avançats en Història de l'Art. Universitat de Barcelona, 2010. También, a raíz de colaborar con el grupo de investigación de Historia Moderna de la Universidad de Barcelona: Vida Cotidiana en el ámbito doméstico durante el Antiguo Régimen. La España Mediterránea. Proyecto de Investigación: HUM2005-06472-CO2-02/HIST. Departamento Historia Moderna. Universidad de Barcelona.
} 
mejores y más ricos objetos y muebles. Además, estas representaciones organizadas por miembros de las clases altas emulaban las que se celebraban en el teatro estatal, el Teatre de la Santa Creu de Barcelona y seguían su mismo esquema.

\section{PROCESO DE UNA REPRESENTACIÓN TEATRAL, EN UNA CASA NOBLE}

Por el manuscrito de D. Rafel D'Amat i de Cortada, Barón de Maldà ${ }^{2}$ conocemos el proceso seguido ante la representación y ensayo general de una obra de teatro en su propia casa, hablamos de la tragicomedia El Delincuente Honrado, obra escrita por Gaspar Melchor de Jovellanos hacia el año 1770, representada el mes de febrero de 1786, en la Primera peza baix dels Estudis, habitació de mon germà, de Casa Cortada. Se trata, por lo tanto, de una representación teatral en una casa aristocrática de la ciudad de Barcelona, acaecida a finales del siglo XVIII.

Una vez la familia Cortada decidió que representaría una obra, lo primero que debieron hacer era escoger cuál, decisión que podía tardar en tomarse varias noches. Acto seguido se compraron los libretos de la comedia, en este caso en la tienda de Gilbert Llibreter de Barcelona, para más tarde repartir los papeles -normalmente entre familiares y amigos de la casa- procurando adaptarlos al carácter de cada una de las personas que iban a representarla, a las cuales se convocaba durante varios días para proceder a los ensayos, los cuales se realizaron en uno de los estrados de la casa, procediendo primero a estudiar individualmente sus respectivos papeles para más tarde empezar los ensayos generales. No se contentaron con representar la tragicomedia y un sainete, $\mathrm{y}$ añadieron tonadillas o tiranas de gust copiando la fórmula del teatro público, precisando para ello de la colaboración de los Señores Ignasi Plana, notario y autor teatral, y Thomas Presas mestre del teatro de Comedias de Barcelona. El primero trabajó la adaptación de los versos y el segundo la música, labor que se desarrolló en el retrete $^{3}$ del hermano del barón.

Una vez convencidos de la viabilidad de llevarla a cabo, se procedió a solicitar la presencia de un maestro carpintero, acompañado del oficial y también de un aprendiz, con el fin que llevaran bancos, caballetes de madera y otros utensilios y, a su vez, se avisó al Sr. Manuel Tramullas, reconocido pintor, para pintar y disponer los bastidores del teatro acorde con la temática de la obra. A continuación se formó el teatro con la perspectiva de devant, se colgó la pieza de tapicería de Manlleu, con la finalidad que el aposento quedara abrigat, es decir recogido y en armonía con el telón de damasco amarillo. Se armó un palco en la salida del huerto, frente a la escalera, guarnecido con damasco carmesí, para que los representantes ${ }^{4}$ pudieran descansar. Se colocaron en esta estancia y fuera de ella, taburetes de color amarillo, en hilera, quedando de esta manera el espacio apto para la representación.

2. AHCB. D’AMAT I DE CORTADA, R.: Baró de Maldà. Miscel·lània XI. pp. 471-501.

3. El retrete en Cataluña es como el estudio privado junto a la alcoba.

4. Nombre citado en el texto original, entendemos para denominar a los actores amateurs o aficionados. 
Realizadas óptimamente las pruebas de la tragicomedia, sainete, tonadillas y tiranas con música de viola y de violines, se decidió finalmente comenzar el ensayo general el día 17 de febrero. Previamente, los actores habían invitado a diferentes personas, y conocidos, además y para sorpresa del propio barón, de una cantidad importante de cambreras, las cuales formaban parte del servicio en las casas de los representantes, además de algún capellán $\mathbf{y}$ menestrales vestidos con mantellinas y casacas, muchos de los cuales habían acudido a raíz de propagarse la noticia por Barcelona, según palabras del propio barón: ab això tal bum bum se escampà per Barcelona. El día 18 de febrero, se representó para los Señores y Señoras, tal como los cita D. Rafael d'Amat, familiares directos y para otras personas relacionadas con Casa Cortada. La función comenzó a las 19:30 horas, habiéndose llenado todo el espacio, así como también la estancia contigua. Después de proceder a la afinación de los instrumentos por parte de los músicos, empezaron a tocar la obertura del célebre Hayden. A continuación se procedió a la apertura del telón, dejando a la vista un: Quarto de estudi ab un prestatge al mig de llibres; mapas en las parets; cadiras; y una tauleta, al lado, sentado en una silla se hallaba el hermano del barón, Don Felip, el cual fue el encargado de comenzar la representación de la tragicomedia El Delincuente Honrado.

Al acabar la función se bajó el telón, pero la música continuó sonando durante poco más de media hora, tiempo necesario para cambiar parte del decorado, colocar un estrado y adecuarlo para el sainete La Dama Disciplente de Ramón de la $\mathrm{Cruz}^{5}$ que iban a representar a continuación. Al mismo tiempo, los actores aprovecharon para sacarse las pelucas, peinarse, ponerse vestidos de gala, etc. Se alzó de nuevo el telón y empezó el sainete, que incluyó música y tonadilla, también un juego de prendas. Posteriormente hubo un diálogo cantado, entre uno u otros, para finalizar cantando todo el coro. Se bajó el telón y se dio por terminada la representación.

Los días 21 y 22 de febrero se repitió la función, esta vez para los parientes, interesados y nobleza. También los días 24 y 25 de febrero, para las mismas Señoras y Señores, además de otras personas conocidas. El 27 de febrero (lunes de Carnaval) hubo nuevamente función, pero no sin antes haberse retirado los taburetes de la estancia y habiendo ido a buscar todos los bancos de Sant Felip Neri (iglesia cercana a casa Cortada) para dar cabida a más gente, haciendo caso de los comentarios del Sr. Marqués de Gironella, el cual vaticinó que asistirían muchas personas, a consecuencia de la gran difusión del acto por toda Barcelona. Premonición que se hizo realidad, dado que no sólo se llenó la Peza del Teatro, según nos informa el propio barón, sino que también abundaba la gent del segon, tercer y quart ranch, y per fi en lo tot eran cent y noranta personas. El 28 de febrero, fue el último día de la representación de la tragicomedia, sainete y tonadillas, adelantándose la función una hora para poder finalizar con una cena compuesta por: Sopas ab caldo; Fiambres; Verduras; Rostit; Plata de crema, Dulce de Cuchara, además de postres de almendras, entre otros. Todo dispuesto en una mesa muy bien puesta con limpios manteles, en el centro bandejas de plata, además de

5. Se trata de una obra de Ramón de la Cruz catalogada también bajo el título de La Señorita Disciplente. 
una buena iluminación y música de fondo. No todos los comensales pudieron degustar de la cena en sillas, pero se las ingeniaron para cenar lo más cómodamente posible. Finalizada la cena, todo el mundo marchó a sus casas o posiblemente la gente joven siguió divirtiéndose en alguno de los saraos de Carnaval, según hipótesis del barón. El documento de Rafel d'Amat nos permite seguir con detalle todo el proceso de creación teatral y la sucesión de actos sociales que genera.

\section{REPRESENTACIONES TEATRALES SEGÚN LOS DIFERENTES GRUPOS SOCIALES}

La grandilocuencia formaba parte de la organización de estos actos sociales, pues uno de los motivos principales para su realización, como hemos dicho anteriormente, era mostrar el poder de sus anfitriones, que quedaba explícito no tan sólo en la riqueza de la escenografía y decorados, sino también al contratar a los artistas más relevantes del momento, en la vestimenta y pelucas utilizadas, en el imitar totalmente el esquema de función del teatro público, y, especialmente en la magnificencia de la cena, y, en la invitación a personalidades, como en esta caso a la Sra. Capitana de Calatrava. La frase del propio barón, anfitrión y protagonista del acto social: fou la folia real, evidencia esta voluntad de mostrar el estatus y por su comentario de satisfacción y admiración queda claro que cumplió todas sus expectativas.

Evidentemente estamos hablando de la nobleza catalana del siglo XVIII, pero podemos extrapolarlo a las clases emergentes que surgieron en el siglo XVIII con el incremento del comercio en ultramar, la expansión de la marina y la abundancia de las industrias que propiciaron una época de bienestar, aunque desvirtuada por las guerras, y que originó la creación de nuevas fortunas. Esta nueva clase social se hizo construir edificios propios que evidentemente decoraron con los mejores objetos y mobiliario, con una clara voluntad de competir con la nobleza y, también, organizando reuniones caseras. Es el caso del tintorero Felip Nadal, el cual además de contar para las representaciones teatrales en su casa de Sarrià con actores aficionados, disponía de una compañía de actores profesionales que ofrecían un repertorio fijo y una temporada teatral nutrida y dilatada, lo cual provocaba el deleite de sus invitados, costumbre que llevaba a término por conveniencias de su negocio pero sobre todo por su afán de relacionarse socialmente. Este teatro junto con el de Jeroni Borràs y el del Barón de Maldà fueron los más importantes del momento ${ }^{6}$. En cuanto a la escenografía, Nadal contrató en ocasiones a otro pintor reconocido: confiat al cèlebre Montanya. El dato que confirma la importancia de este teatro y, el nivel económico de su propietario, es el hecho de que fuera permanente, el único que pervivió en el tiempo, aunque es de suponer que hubo otros. Queda confirmado cuando comprobamos que en casas aristocráticas una y otra vez se opta por una escenografía efímera, como sucedió en Casa Rocafort, para la representación de la comedia Lo Huérfano de la China el 26 de abril de 1800: Lo teatro

6. CURET, F.: Teatres particulars a Barcelona en el XVIIIe. Barcelona, 1935, p. 63. FÀBREGAS, X.: Les formes de diversió en la Societat Catalana Romàntica. Barcelona, 1975. p. 72. 
que queda al mig de la peza, queda reduit a un telon de cotonadas pintadas, y obert ab un à modo de estrado (...) ${ }^{7}$.

Tenemos también constancia en Barcelona de un teatro semi-permanente instalado en el salón del antiguo Palau dels Templers i de la Comtessa.

(...) Els vescomtes varen habilitar aquesta sala per donar-hi representacions teatrals d'un refinat gust artístic, a les quals hi assistia el bo i millor de l'aristocràcia8.

En el caso de los menestrales, al no disponer de medios, eran ellos mismos los encargados de la puesta en escena, desde el vestuario hasta la escenografía:

Els mateixos intèrprets, junts amb socis del taller qui pintaven el decorat, engiponaven el vestuari $i$ arranjaven els altres elements necessaris d'una manera que ara en diríem sintètica? .

\section{EXISTENCIA DE TEATROS PARTICULARES EN BARCELONA Y SUS LEGISLACIONES}

Aunque no se han conservado demasiadas fuentes sobre el tema, aquellas de las que disponemos acreditan que se realizaban representaciones teatrales en el ámbito privado, y nos permiten realizar un listado de todos aquellos teatros particulares existentes en Barcelona durante el siglo XVIII y hasta mediados del siglo XIX, que incluye todas las clases sociales ${ }^{10}$. Comprobamos que a pesar de las diferentes legislaciones existentes contra la puesta en marcha y el funcionamiento de teatros particulares, el listado de teatros que hemos podido recoger es extenso. La Real Cédula del 25 de enero de 1771, contemplaba que solamente el Hospital de la Santa Creu de Barcelona podía

7. Ibidem, p. 70.

8. Ibidem, pp. 62-64.

9. Curet, F.: Història del Teatre Català. Barcelona, 1967, p. 120.

10. Detalle de los teatros particulares, de los que tenemos constancia, aunque es muy probable que hubieran muchos más: El de Felip Nadal, a Sarrià, Palacio de los Duques de Alba y Marqueses de Vélez, Baró de Maldà (Casa Cortada) en la calle del Pi, Jeroni Borràs, de la misma calle, Vives de la Calle Canuda, Barones de Rocafort en la Rambla, Sanjuan de la Riera de Sant Joan, Tarancó, Junyent, dels quatre cantons de Bellafila, Ignasi Plana, de la calle dels Banys, Ramón Gual, (también lo encontramos como Igual) dels Escudelleres delante de la casa del Marqués de Ciutadilla, cerca de la Plaça de la Verònica, Duques de Sessa, en la calle Ample, Erasme de Gonima, en la calle del Carme y también en su torre de Sant Feliu de Llobregat, Cermeño, después de Canaleta, de la calle de Sant Pere més Baix, Bacardi, Casa Renart, también en la calle Montesión, y la casa de Bernardo de las Casas, de la calle de la Plata (estos dos quizás de cronología más avanzada, pues son citados por Conrado Roure). En cuanto a locales, seguramente alquilados por los menestrales, encontramos: Plaça de la Font o dels Boters, de la Barceloneta (quizás en el almacén de Valentí Riera o en un patio interior), Magatzem de la Palla, de la calle Xuclà, cerca de la iglesia de Betlem, Plaça de Jonqueres, Almacén de una fábrica de la calle Trentaclaus, Casa Vivas, de la calle Canuda (donde se hacían Comedias y saraos), Cuadra de una fábrica de la Calle Més Baix de Sant Pere, esquina con la calle de Fonollar, Calle dels Escudillers, Tercer piso de una casa de la calle de Mercaders, Plaça de Bonsuccés, delante del Convento de Frailes Servites, Calle de Ramelleres, Calle d'en Robador, Carrer o Placeta de les Mosques, Calle del Hostal de Manresa, local de la Calle d'en Tripò, Assaonadors. Más información: RUIZ, N.: Els teatres particulars.... pp. 65-72. 
organizar representaciones teatrales. La Real Orden del 19 de marzo de 1790 prohibía cobrar entrada en los espectáculos celebrados en casas particulares:

(...) no se pueden promover ni representar Comèdies caseras, ni Bayles, academias (líriques). Sombras, máquinas, ni otras diversiones en casas particulares a escote o por dinero (...) bajo la pena de 50 ducados a los contraventores, y dos meses de cárcel $(\ldots)^{11}$.

Durante la ocupación francesa, el gobernador Maurice Mathieu decretó el 20 de noviembre de 1810 que: ningún espectáculo de sociedad particular, podrá darse en ningún otro paraje sino en la casa Teatro ${ }^{12}$. Fernando VII, con la excusa de impedir conspiraciones, dictó en el año 1829 una Circular:

Habiéndome cerciorado que en ciertas villas del principado se han abierto teatros de aficionados (...) llegando el escándalo a representar piezas y sainetes que no tienen otro objeto que entretener la disipación, distraer de ocupaciones útiles, y corromper las costumbres públicas (...). Añadiendo: (...) es llegado el caso de poner coto a este desenfreno, y contener con mano fuerte los peligros y vicios a que tales reuniones teatrales dan lugar (....) (...) que hagan desde luego cerrar los expresados teatros, y no los permitan abrir en lo sucesivo por estar particularmente privado por las leyes y Reales pragmáticas vigentes $(\ldots)^{13}$.

Ninguna de estas órdenes oficiales pudo frenar la actividad teatral en estos espacios privados. Además del agravante que en las casas particulares sólo podían celebrarse representaciones en épocas determinadas del año y coincidiendo con el cierre del teatro público ${ }^{14}$ o pidiendo permiso: Se fan en Barcelona algunas diversions caseras, que las componen menestrals ben avinguts, de estas, ab lo permis de S.E. lo General $(\ldots)^{15}$.

Las Reales Ordenes se dictaron como consecuencia de que el teatro en el Estado Español se había instituido de forma oficial, iniciándose su proceso durante el reinado de Felipe II, el cual creó una fórmula para subvencionar los hospitales otorgando el monopolio de pago a estas instituciones. Gracias a estos ingresos los hospitales se autofinanciaron en una parte bastante significativa. El Hospital General de Barcelona

11. Sala-VAlldaura, J. Mª Cartellera del Teatre de Barcelona (1790-1799). Barcelona, 1999, pp. 15-16. El Teatro en Barcelona entre la Ilustración y el Romanticismo. O Las Musas de Guardilla. Lleida, 2000, p. 34.

12. Ibidem, p. 35 .

13. ARTís, J.: Tres conferències sobre Teatre Retrospectiu de Catalunya. Barcelona, 1933. pp. 35-37.

14. Los objetivos del Estado y de las clases dominantes de la época fueron la vigilancia y control de las costumbres y tradiciones del pueblo. Se trataba de crear una cultura dirigida desde el poder a base de una legislatura prohibitiva, con la intención de controlar cualquier manifestación popular, que evidentemente también afectó al teatro y que comportó que muchas fiestas tradicionales pasaran a celebrarse en espacios particulares u otros espacios. Entre las relativas al teatro, mediante la Real Cédula de 1765, se prohibieron los Actos Sacramentales por el temor por parte de la iglesia de los excesos del teatro, a los vestuarios inadecuados y la correlación entre las vidas privadas de los cómicos y los papeles sagrados que representaban. El año 1788 se prohibieron también las comedias de santos y se amplió la prohibición a las comedias de magia, aunque sin demasiado éxito. ANDIOC, R.: Teatro y Sociedad en el Madrid del siglo XVIII. Madrid, pp. 345-379. Más información: RUIZ, N.: Los teatros particulares... p. 78.

15. AHCB. MS. A. 220. Calaix de Sastre XX, 1800 (1 gener-30 juny) Fons Artís. 
fue el promotor, debido a los muchos gastos que comportaba su actividad. Para ello se dirigió al Virrey Fernando de Toledo para pedir ese privilegio, que fue otorgado el año 1579, y ratificado por Felipe II, el 25 de julio del año 1587 mediante la Real Cedula $\mathrm{y}$, también, con el Decreto de fecha 19 de junio de 1589. A partir de esta normativa se hizo obligatorio que cualquiera que quisiera hacer teatro público precisaba pedir permiso al Hospital debiendo a cambio formalizar un pago que, según parece, era bastante elevado. Se supone que el monopolio fue vigente en todo el Estado Español, hasta el año $1833^{16}$ con la instauración del liberalismo. En Barcelona, aparecieron nuevos coliseos, muchos de los cuales ocuparon edificios abandonados con la desamortización de bienes de Mendizábal el año $1835^{17}$, que transformó totalmente el panorama teatral, provocando la desaparición progresiva de los espacios privados.

El año teatral oficial comenzaba el domingo de Resurrección y terminaba al entrar la Cuaresma, el miércoles de Ceniza. Constaba de dos temporadas que se enlazaban durante el mes de septiembre. A diferencia de Madrid, en Barcelona los actores profesionales no disfrutaban de vacaciones y sólo podían descansar durante la Octava de Corpus, por Todos los Santos y durante la Cuaresma, o sea cuando el teatro permanecía cerrado de manera oficial o por causas graves imprevistas, como el fallecimiento de un rey. En el Teatre de la Santa Creu, una función normalmente consistía en: una comedia y baile, o bien comedia, tonadilla y sainete, también se hacía opera y baile, o una academia, o bien, comedia y academia, y, finalmente en una mezcla de piezas ${ }^{18}$.

\section{SITUACIÓN DEL TEATRO EN CATALUÑA Y RECUPERACIÓN DE UN TEATRO EN LENGUA CATALANA}

La llegada de los Borbones a Cataluña supuso la prohibición de la lengua catalana y como consecuencia en el teatro público sólo estaban autorizadas obras representadas en castellano. En realidad, el repertorio consistía en obras de autores castellanos, especialmente de Gaspar Melchor de Jovellanos y Leandro Fernández de Moratín, pero también se escenificaban traducciones de obras clásicas francesas e italianas, las cuales gozaban de una gran aceptación por los sectores más cultos de la sociedad barcelonesa. Ahora bien, la mayoría de historiadores de teatro, coinciden en que, durante los intermedios o bien en el cierre de la función, se representaban piezas breves de carácter cómico o costumbrista como sainetes en bilingüe y, avanzando en el tiempo, sólo en catalán.

En el ámbito privado, parece ser que en las casas aristocráticas se tendía a imitar el repertorio del Teatre de la Santa $\mathrm{Creu}^{19}$ y por lo tanto la mayoría de obras representadas eran en castellano y también traducciones de obras francesas, aunque a finales

16. MASSIP, F.: Història del Teatre Català. 1 Dels orígens a 1800. Tarragona, 2007, p. 317.

17. FÀBREGAS, X.: Història del Teatre Català. Barcelona, 1978, p. 99.

18. Suero RocA, M. T.: El teatre representat a Barcelona de 1800 a 1830. Vol. 1. Barcelona, p. 227.

19. A lo largo de la historia este teatro ha tenido diversos nombres. Ver: CURET, F.: Visions barcelonines, 1760-1860. Les Rambles Passeig i Jardins. Barcelona, 1952, p. 62. 
del siglo XVIII estas clases sociales introdujeron también obras en catalán. Otra de las razones que favorecían las representaciones en castellano fue que esta lengua se había impuesto entre las clases dominantes catalanas, al estar supeditadas al poder central y, por el hecho de haber estado suprimidas las instituciones culturales catalanas tras la Guerra de Sucesión. Todos estos factores comportaron la inexistencia de un teatro culto en lengua catalana salvo algunas honorables excepciones que encontramos en Menorca y la nombrada Cataluña Norte, aunque un grupo reducido de escritores y dramaturgos continuaron escribiendo en catalán. En consecuencia el teatro catalán en este periodo se componía de obras de carácter burlesco o religioso, representadas en ámbito privado y popular.

No todas las clases sociales hablaban o entendían el castellano, razón por la cual es evidente que entre las clases más bajas las representaciones teatrales de cualquier género fueran representadas mayoritariamente en privado, en catalán: (...) que encara que el breu teatre català havia de competir sovint amb els sainets castellans, el seu àmbit són les festes privades $i$ col-lectives (... $)^{20}$. Por otro lado, los entremesos y sainets ${ }^{21}$ eran géneros que gozaban de la aceptación de este público, puesto que reflejaban la vida cotidiana, las costumbres, los gestos, en definitiva eran obras más cercanas y por tanto las preferían a un teatro más erudito: es muntaven els espectacles del teatre breu català més proper als sainets o als entremesos castellans coetanis, representats a la casa de les Comèdies de Barcelona ${ }^{22}$. Además, resultaban más fáciles y económicas de representar ya que no requerían de una gran escenografía.

Los historiadores del teatro catalán del periodo coinciden en que estas representaciones eran escenificadas en el ámbito particular, interpretadas por grupos de aficionados de todas las clases sociales, llegando a ser el detonante o el precursor de la recuperación del teatro catalán del siglo XIX, dentro de la eclosión del Romanticismo, y especialmente, en la Renaixença. En cuanto a los autores protagonistas de esta recuperación, todavía incipiente, que no fue consolidada hasta décadas más tarde con las aportaciones fundamentales de Frederic Soler, conocido en sus inicios como a «Serafí Pitarra», cabe mencionar de manera principal a Francesc Renart i Arús y a Josep Robrenyo i Tort ${ }^{23}$. También hemos de considerar artífice de esta renovación al notario Ignasi Plana. La principal característica de Ignasi Plana y Francesc Renart i Arús fue la utilización de las dos lenguas. Así, escribieron piezas en catalán, en castellano y bilingües, aunque con el paso del tiempo Francesc Renart se inclinó por escribir sola-

20. Sala-Valldaura, J. Ma.: Teatre Burlesc Català del segle XVIII. Barcelona, 2007, p. 23.

21. MASsIP, F.: Història del Teatre Català...pp. 301-309. Para más información sobre denominación y características de este género.

22. Sala-VAlldaura, J. M a.$:$ Teatre Burlesc...p. 24.

23. Diaz de Escovar, N, Lasso De La Vega, F. de P.: Historia del Teatro Español. ComediantesEscritores-Curiosidades Escénicas. Apéndice sobre los Teatros Catalán y Valenciano por BERNAT Y DuRAN, J.: Tomo Segundo, Barcelona, 1924. pp. 339-355. 
mente en catalán. Por otro lado tenemos constancia de que estos autores organizaban representaciones en sus casas ${ }^{24}$.

\section{CAMBIOS DE HÁBITOS Y COSTUMBRES SOCIALES}

La recuperación económica producida durante la segunda mitad del siglo XVIII, como consecuencia, entre otras razones, de la autorización por parte del régimen borbónico de levantar la prohibición de comerciar con América, favoreció, entre otros factores, una mayor actividad teatral. Esto podría explicar la proliferación de teatros particulares y de aficionados en una cronología tan avanzada del siglo XVIII.

Además las nuevas costumbres llegadas del extranjero fomentaron las relaciones sociales y la costumbre de recorrer todas las estancias de la casa, que incluía las más privadas, como los estudios, tocadores y dormitorios, lo cual conllevó una multiplicación de alcobas y salas de recibir contiguas a las grandes salas que recibían el nombre de estrado, el mismo nombre que las antesalas de las alcobas ${ }^{25}$. Por otro lado, estos espacios, en las dos últimas décadas del siglo XVIII, se adaptaron al nuevo estilo artístico. Así, observamos que los marcos de separación de las alcobas que hasta el momento separaban las dos estancias fueron sustituidos por una separación arquitectónica con puertas vidriadas, con frecuencia correderas para no ocupar espacio en la alcoba, normalmente con puertas laterales de paso y las decoraciones a base de óvulos, lazos y copas de inspiración clásica, combinando el dorado con la pintura de tonos suaves, de color blanco marfil, amarillo, claro o gris ${ }^{26}$.

Cabe destacar que en este siglo fue precisamente el dormitorio, entendido como un conjunto de espacios, quien acogió parte de las nuevas tipologías de mobiliario del periodo: la cómoda, el canapé y la cornucopia. No podemos detallar cada uno de los objetos o tipologías de mobiliario que contenían estos espacios, pero sí destacar la voluntad de sus propietarios en engalanarlos, dado que se habían convertido en lugares de recepción para reuniones sociales, a la vez que para mostrar su estatus económico. Las visitas, en su deambular por la casa, admiraban la categoría de la misma, pero al entrar en el dormitorio la mirada les conducía hacía el centro de la alcoba donde se hallaba situada la cama cubierta y adornada con ricas telas -el mueble más importante de este espacio- dado que el conjunto ofrecía un efecto totalmente escenográfico. En cuanto a la ante sala o estrado, encontramos diversas tipologías de mobiliario, como las consolas con su espejo, mesitas, cómodas -símbolo de riqueza ya que no todo el mundo podía disponer de ellas-, que convivían con otros muebles de estilos y estéticas

24. El día 4 de setiembre de 1798, en casa de Joseph Renart, fue representada una pieza cómica. AHCB MS A 218. Calaix de Sastre XVIII (1 gener-30 juny) Fons Artís. En el caso de Ignasi Plana, aunque no hemos encontrado ningún documento que explique una representación en su casa, se constata al figurar en el listado de los teatros particulares existentes en Barcelona, que indica el de Ignasi Plana en la calle del Banys.

25. Piera, M, Mestres, A.: El Moble a Catalunya. L'espai domèstic del Gòtic al Modernisme. Manresa. 1999, pp. 126-129.

26. Ibidem, p. 143. CURET, F.: Visions barcelonines... p. 58. 
más antiguas y diversas. Todos ellos realizados con los más ricos materiales y técnicas, sin olvidar otros objetos como relojes, imágenes religiosas y porcelanas que decoraban estas estancias. Un signo que muestra esta voluntad es el hecho que en las reuniones sociales no cerraban la cortina o puerta de la alcoba, todo al contrario, la dejaban abierta para que el mueble más caro de la casa -la cama- se mostrara en todo su esplendor ${ }^{27}$.

Destacar la silla, una tipología de mobiliario que encontramos repartidas en cantidades considerables en las casas, dada su utilidad en las reuniones sociales. Los anfitriones especialmente de las clases altas, procuraban tener una cantidad importante, pero en el supuesto de no disponer de suficientes no dudaban en pedirlas prestadas a sus familiares o amigos, incluso a la parroquia o en última instancia alquilarlas. En cuanto a las representaciones teatrales entre los menestrales, como sus casas lógicamente eran de dimensiones más reducidas, no disponían de sillas suficientes, por este motivo las pedían a sus vecinos: Limitada era també llur capacitat, així no sembla que la cabuda pogués excedir de vint o trenta espectadors, per a donar seient als quals deuria caldre manllevar cadires a casa dels veïns ${ }^{28}$.

Nos interesa remarcar especialmente el dormitorio como un espacio multifuncional, dado que este había asumido desde siempre múltiples funciones. Se trataba del lugar donde transcurría el ciclo de la vida del individuo, desde el nacimiento hasta la muerte, y donde podía desarrollarse buena parte de la vida personal y social de este. Además de rezar, padecer y/o curar enfermedades y realizar actividades relacionadas con la higiene corporal como peinarse o afeitarse, también se podía leer, escribir, firmar documentos, jugar a las cartas o tomar chocolate, y, evidentemente era el lugar indicado para las intimidades amorosas. En definitiva, costumbres, modas, reuniones sociales de todo tipo que podían incluir hasta representaciones teatrales. Cada una de estas actividades conllevaba la transformación del espacio, adaptándose a cada una de las funciones, bien en un espacio sanitario, religioso, un mundo cerrado de mujeres, etc. En el caso de las representaciones teatrales, convirtiéndose el dormitorio en un espacio de sociabilidad y para el ocio.

\section{LA EVOLUCIÓN DEL CONCEPTO SALA Y ALCOBA}

Evidentemente no todas las representaciones teatrales se realizaban en este espacio, pero resulta interesante cuando en las fuentes documentales encontramos el concepto teatro de sala y alcoba o representaciones de sala y alcoba y, una vez realizado un estado de la cuestión ${ }^{29}$, podemos confirmar que era un espacio utilizado con frecuencia

27. PIERA, M.: Audacia i Delicadesa. El Moble de Torroella de Montgrí i l'Empordà (1700-1800). Torroella de Montgrí, 2008, p. 75.

28. FÀBREgAS, X.: Les Formes de Diversió... p. 76.

29. Curet, F.:Teatres particulars... pp. 91-92. FonT, M.: El teatre català anterior a Pitarra: Josep Robreño, Francesc Renart, Abdon Terrades. Barcelona, 1928, pp. 5-6. FÀBREGAS, X.: Les formes de diversió... p. 73. Ibidem, p. 76. Ibidem, p. 165. MASSIP, F.: El teatre català del segle XVIII a PANDOLFI, VITO. Història del Teatre, vol. II. Barcelona, 1989-1993, p. 41. FÀBREGAS X.: Les formes... p. 77. GALLEN, Enric.: Els Orígens del Teatre Català Modern, en PANDOLFI, Vito. Història del Teatre, vol. II. Barcelona, 
por todas las clases sociales catalanas para llevar a término las representaciones teatrales. En el caso de los menestrales, cuando no podían representar comedias en sus casas por falta de espacio, se veían obligados a alquilar locales como: "Una sala $i$ alcova, un magatzem, la quadra d'una fàbrica, una sala de ball, el patí d'un cafè, unes golfes...» ${ }^{30}$. Aunque la práctica de alquilar no era exclusiva de este colectivo.

No sabemos la fecha exacta en que aparece este concepto, pero nuestra hipótesis lo relaciona con las representaciones teatrales de sombras chinescas en el ámbito priva$\mathrm{do}^{31}$. La primera noticia de una representación en Barcelona de este género, se remonta al año 1786, momento en que se realizó una exhibición en una casa de la calle Ample y probablemente se sucedieron las representaciones en los días y meses siguientes ${ }^{32}$. Comentario que avala la prohibición de 1790 de llevar a término este tipo de representaciones caseras mediante pago. Sin embargo no será hasta la Cuaresma del año 1800 cuando encontramos noticias concretas sobre unas representaciones que se hicieron en el Teatro de la Santa Creu de Barcelona, a cargo de una compañía de circo de origen italiano, dirigida por Francesco Frescara acompañado de un hombre llamado Sandro Chiarini, aunque sin demasiado éxito. Un año más tarde Chiarini se presentó con su propia compañía y se puede considerar que fue el inductor de las sombras chinescas en Cataluña o al menos fue quien le otorgó un carácter familiar y particular. Este género, parece ser, fue muy aceptado por todas las clases sociales y una de las diversiones preferidas de la época, como explican algunos de los asistentes a estas funciones, caso de Josep Coloreu y Conrado Roure.

Las familias más acomodadas fueron las primeras en organizar sesiones de sombras chinescas en sus casas, solicitando y disputándose el servicio de profesionales. La asistencia a estas representaciones sólo estaba permitida mediante invitación, siguiendo el protocolo establecido para otras reuniones sociales de carácter privado. Más tarde fueron acogidas también por los menestrales ${ }^{33}$. Parece ser que para escenificar estas representaciones, los espacios domésticos escogidos fueron las salas y alcobas:

1989-1990, p. 239. Morell i Montardi, C.: El Teatre de Serafi Pitarra: Entre el Mite i la Realitat (1860-1875). Barcelona, 1995, p. 12. IÑIgUEZ, BARRERA, F.: La Parodia Teatral en España (1868-1914), Sevilla, 1999, p. 52. SAlA-VALldAuRA, J. Ma .: El teatre de la Il-lustració... p. 176. JANÉ, J.: Les Arts Escèniques a Catalunya. Barcelona, 2001, p.17. Rossich, A.: El Teatre Català dels Orígens al segle XVIII. Actes del II Col·loqui. Problemes i Mètodes de Literatura Catalana Antiga: «Teatre Català antic». Girona, 6 al 9 de juliol de 1998. Universitat de Girona. Institut de Llengua i Cultura Catalanes. Edition Reichenberger, Kassel, 2001, pp. 87-88.

30. CURET, F.: Teatres particulars... p. 91-92. Más información: Estado de la cuestión de los Teatros de Sala y Alcoba: RuIZ, N.: Els Teatres Particulars...pp. 45-49.

31. Ibidem, pp. 112-113.

32. CURET, F.: Visiones barcelonines. I. La vida a la llar. Barcelona, 1981, pp. 214-218.

33. Amades, J.: Titelles i Ombres Xineses. Les Ombres Xineses. Barcelona. Vol. VII, 1933, pp. 47-83. Ibidem, pp. 80-82. YXART, J.: Obres Catalanes. Col·lecció tríade de Joseph Yxart. Barcelona. 1895, p. 250. Ibidem. pp. 243-253. CuRET, F.: El Arte Dramatico en el resurgir de Cataluña. Barcelona, 1917, p. 71. CurET, F.: Historia del Teatre Català...pp. 117-120. ArTís, J.: Tres Conferències ...p. 17. FÀBrEGAS, X.: Les formes de diversió... p. 77. AA.VV. LLORET I ESQUERDO, J. GARCÍA J. CÉSAR O. CASADO GARRETAS, 
(...) organizaban funciones de sombras o de muñecos. (...) El local obligado casi siempre para esta clase de espectáculos familiares era alguna de las salas con alcoba que las moradas de aquellos tiempos todas poseían. La alcoba era la parte destinada a escenario. $\mathrm{Su}$ boca eran los montantes que separaban las dos habitaciones. Para habilitarla no había más que cubrir la parte inferior de los mismos con una tela sujeta a un larguero y colocar unas cortinas correderas, como telón, en el hueco superior. Si se trataba de hacer sombras en lugar de muñecos, se sustituían las cortinas correderas por una tela blanca, untada de aceite para que fuese más transparente, y, que se colocaba muy tirante (...) En esta disposición quedaba convertida en escenario y aislada de la sala. En esta se colocaban sillas en hilera y se destinaba a los espectadores ${ }^{34}$.

A pesar de que su autor se está refiriendo al año 1860, el dato confirma que se realizaban funciones de sombras en este espacio y su pervivencia. Por otro lado, nos muestra que la utilización de la sala y alcoba surge casi obligada por las características propias de este tipo de representación, que precisaba de un espacio donde poder esconderse los manipuladores de las sombras y seguramente por la similitud de este espacio con un teatro: Alcoba-Escenario, Sala-Platea. El mismo Conrado Roure comenta que con el tiempo estos «teatrets d'ombres» se convertirían en teatros para representar espectáculos con actores:

Las alcobas fueron provistas de banquetas de medio metro de altura, sobre las que se extendían tablas de madera, convirtiéndose en escenarios de reducidas dimensiones, pero suficientes para que los actores se hallaran algo elevados sobre el auditorio y para que pudieran moverse, aunque de una manera parca y comedida ${ }^{35}$.

El concepto de teatro de sala y alcoba lo encontramos en las fuentes consultadas tratado de manera central o circunstancial, asociado con la recuperación del teatro en catalán, de manera incipiente en estos ámbitos privados. Al mismo tiempo que confirman que las representaciones teatrales eran una de las diversiones más arraigadas en todas las capas sociales, además de una excusa para las relaciones sociales. Así, Melcior Font, hablando de los sainetes «casolans» de Francesc Renart i de Josep Robrenyo dice: (...) que són a fi de comptes les bases del teatre modern, abans de la Reinaxença Catalana. (...) fou superat d'un salt el teatre d'aficionats, que no era sinó una prolongació de les tertúlies casolanes, d'aquelles representacions de sala i alcova, pretext per a la xocolata $i$ els secall ${ }^{36}$. Xavier Fàbregas se refiere a las agrupaciones de aficionados y corrobora la necesidad de este colectivo de alquilar diferentes locales con la finalidad de ensayar y representar las obras añadiendo:(...) i, quan la representació era estrictament privada, a les sales $i$ alcoves ${ }^{37}$. Enric Gallen nos dice con respecto al

À.: Documenta Titeres. Alicante, 1999, p. 32. SAla-VAlldaura, J. Ma .: Cartellera ...pp. 15-16. SALA-

Valldaura, J. Ma.: El Teatro en Barcelona ... p. 34. JAnÉ, J.: Les Arts Escéniques a Catalunya... p. 55.

Más información del Teatro de Sombras Chinescas: RuIZ, N.: Els Teatres Particulars...pp. 49-54.

34. Roure, C.: Como nació el Teatro Catalán. Recuerdos de mi larga vida. Barcelona, 1925, pp. 7-9.

35. Ibidem, pp. 7-9.

36. FONT, M.: El teatre català anterior... pp. 5-6.

37. FÀBREGAS, X.: Les formes de diversió... p. 73. 
sainete catalán y los menestrales: (...) si be tenim noticia que en els espais habilitats per la menestralia -sala i alcova- (...) es produïren les primeres peces del teatre català modern ${ }^{38}$. También Carmen Morell relaciona las representaciones caseras de sala $\mathrm{y}$ alcoba con las representaciones en catalán en estos espacios y Francisca Iñiguez dice: (...) en la bulliciosa intimidad de los talleres, en las representaciones de lo que dio en llamarse sala y alcoba iban formándose los elementos vivos del teatro catalán ${ }^{39}$. Albert Rossich, por su parte, al hablar del teatro en Cataluña durante el siglo XVIII, afirma que en Barcelona proliferaban los escenarios, a veces clandestinos, y sobre todo particulares, unos locales sencillos e improvisados, que denomina «de sala $i$ alcova» añadiendo que eran los únicos que aseguraban una programación ecléctica al margen de la escena oficial ${ }^{40}$. Josep $\mathrm{M}^{\mathrm{a}}$ Sala-Valldaura nos informa de dos obras La más heroica barcelonesa, Santa Eulalia de Ignasi Plana y El barber que ha tret en la rifa dels porcs de Manuel Andreu Igual, las cuales fueron representadas en el Teatre de la Santa Creu, y afirma: No hay duda que se debió representar en casas particulares sobre todo por la general afición al teatro de alcoba, a las relaciones y a interpretar piezas breves ${ }^{41}$.

Tanto Conrado Roure como Albert Rossich nombran como local obligado para algunos espectáculos familiares la sala y alcoba, y, consultado el diccionario a la voz sala leemos: Local para diversos usos, por ejemplo para espectáculos o conferencias ${ }^{42}$.

Por todo lo dicho resulta interesante constatar que se denomina bajo la misma expresión sala y alcoba tanto al espacio de la casa, propiamente dicho, como a esos locales alquilados para representar las funciones, como también las representaciones caseras. Para Xavier Fàbregas la importancia de esta manera de hacer teatro no provenía por tanto de las posibilidades de los locales, sino de su propio nombre, y añade que no había escalera de vecinos que en los días festivos no tuviera en funcionamiento un teatret $\mathrm{u}$ otro de sala $i$ alcova, hasta tal punto que se hizo popular el dicho: ¿Es aquí que fan comèdies?, frase que se utilizaba al llamar a la puerta de la casa donde se iba a realizar la representación ${ }^{43}$. Añade Xavier Fàbregas:

En aquests locals va fer fortuna un gènere que havia arribat a Barcelona a finals del segle XVIII de mà d'artistes italians: el teatre d'ombres xineses. El procediment per aconseguir els efectes cinètics propis d'aquest espectacle era el següent: L'embocadura de l'escenari ó sigui, l'espai ocupat per la porta corredora en els teatres de sala i alcova, era ocupada per un llençol $(\ldots)^{44}$

Evidentemente los lugares más idóneos para realizarlas, en estos hogares eran las salas y alcobas, por sus propias características, ya que evitaba tener que montar basti-

38. Gallen, E.: Els Orígens del Teatre Català Modern... p. 239.

39. IÑIgUeZ, BARrerA, F.. La Parodia Teatral en España (1868-1914)...p. 52.

40. Rossich, A.: El Teatre Català dels Orígens al segle XVIII... pp. 87-88.

41. SAla-VAlldAURA, J. M a .: El teatre de la Il-lustració... p. 176.

42. Moliner, M.: Diccionario del Uso Español. $2^{\text {a }}$ Edición A-H, I-Z. Madrid, 1998, p. 1010.

43. FÀBREgAS, X.: Les formes de diversió... p. 76.

44. Ibidem, p. 77. 
dores, hacer decorados u otros elementos escenográficos en otros espacios de la casa. Se da la coincidencia que la primera Comedia Ciudadana de Costumbres de la que se tiene noticia parece que fue escrita para estos teatros de sala y alcoba: Qui no adoba la gotera ha d'adobar la casa entera, o sia, mala muller i mala marastra, de autor desconocido (...) Aquesta comèdia sembla que fou escrita en principi per als teatres de sala $i$ alcova, $i$ en coneixem una primera edició del 1833 (... $)^{45}$. Esta fecha resulta muy interesante, dado que si es cierta como afirma su autor, nos encontramos delante de una comedia que se representó primero a nivel particular y posteriormente a nivel público. Por otro lado, resulta interesante que en el año 1833, el concepto teatro de sala y alcoba se hubiera consolidado, porqué a pesar de que sabemos que no todas las obras representadas en casas particulares se realizaban en estos espacios, se hace evidente que este concepto arraigó socialmente. Aunque no tenemos claro de dónde surge esta generalización. Nuestra hipótesis se decanta hacia que el concepto teatro de sala y alcoba surge a partir de la introducción en Cataluña de las sombras chinescas en el ámbito privado y de las representaciones teatrales en estos espacios a cargo, especialmente, de los menestrales.

\section{UN ACTO SOCIAL EN UN ESPACIO PRIVADO}

Hemos podido comprobar que las representaciones teatrales privadas fueron un tipo de diversión aceptada por todas las clases sociales que fomentaron las relaciones en la sociedad catalana. Centrándonos en las clases altas, cabe decir que invertían una suma importante de dinero en cultivar todos los detalles: (...) els pressupostos que els nobles $i$ els rics destinaven a sufragar llurs representacions eran molt alts i inclö̈en decorats dels escenògrafs més importants $(. . .)^{46}$. En realidad, pretendían mostrar su estatus:

(...) la festa teatral podia donar lloc a una certa ostentació de recursos econòmics per part de qui l'oferia, i més d'una vegada sembla que aquest fou un dels objectius principals per a dur-la a terme: confecció de vestits, exhibició de mobles, prodigalitat de lluminària, eren factors de lluïment per a l'amfitrió i prova fefaent de la seva prosperitat econòmica davant d'amics i coneguts ${ }^{47}$.

En el caso de las clases emergentes, las razones para organizar representaciones teatrales en sus casas eran principalmente por conveniencias de negocio o fomentar sus relaciones sociales, como hemos visto, en el caso del tintorero Felip Nadal. Otras razones que podemos contemplar son el especial interés por el teatro, por parte de personas de profesiones liberales, caso de Francesc Renart, y, quizás o simplemente como diversión entre los menestrales:

8 de juliol de 1800: «Francisquet Renart, tenint ab altres sos companys una diversioneta en la habitació de est y de sos pares en lo carrer de l'Hospital, de la comèdia titulada lo

45. Ibidem, p. 165.

46. Sala-VAlldaura, J. Ma.: Teatre burlesc... p. 24.

47. FÀBREGAS, X. : Les formes de diversió... p. 71. 
Cid Campeador, finida esta ab lun divertit Saynete del Amo y Criat, haventme combidat, y à mos Fills, per medi de una atenta esquela, per las 8 de la nit, in puncio ques devia comensar lus donarem gust en assistirhi á veurela, y ohirla, y executat molt bé los actes, ab musica de una viola y 3 o 4 violins en los intermedis y una bells minyons tots los que exian á representar dintre de una alcoba, sens mutació de bastidors, no haventhi si que tapada ab una cortina, y lo Francisquet Renart ab altre jovenent de uns 16 anys, nomenat Juan Prats est últim en lo saynete, vestit de dona(...)» ${ }^{48}$.

Esta cita ilustra notablemente las ideas defendidas en este artículo. Se trata de la representación de una obra de teatro en una casa particular, en este caso de una familia de profesión liberal, la del Sr. Renart, mestre de cases. Además explica que la obra representada fue una comedia, naturalmente en castellano, en cambio el sainete, como era habitual, se representó en catalán y que hubo música en el intermedio. La representación fue realizada por aficionados, concretamente por Renart hijo y sus amigos. Tenemos constancia de ello por la asistencia del propio Barón de Maldà y de sus hijos, los cuales fueron invitados mediante invitación. La representación se realizó en la alcoba, $y$, resulta interesante porque esta aparece citada por primera vez, en el Dietario del Barón de Maldà, precisamente en julio de 1800, fecha que las sombras chinescas se conocían bastamente.

El conocimiento de la existencia de varios teatros particulares, en este caso, en Barcelona, a pesar de las prohibiciones por parte del Estado, demuestran, que las representaciones teatrales privadas disfrutaron de una gran actividad: Com en una ciutat tant gran com es Barcelona no dexa de abundar de diversions caseras, a més de las Públicas $^{49}$. Aunque se trataba de un acto pensado para una minoría, sabemos que anunciaban las representaciones en el Diario local y, que se corría la voz, el bum bum que dice el Baró de Maldà. En cambio observamos que la voluntad de los anfitriones era que estos actos sociales fueran privados, como explicita perfectamente el propio barón a raíz de la representación en su casa de El Delincuente Honrado: No pretenent (...) que fou pública, si que privada, per aquest motiu, convidarem a la gent mitjançant una tarja d'invitació ${ }^{50}$, y, nos sorprende cuando comenta que asistieron 190 personas.

En definitiva las representaciones teatrales privadas, se convertían en una sucesión de actos sociales, desde el momento que se planteaba llevar a término una representación, hasta la finalización de la última función. Queda demostrado que se realizaban en diferentes espacios y locales, incluidas las salas y alcobas, estancias que acabaron creando un concepto teatro de sala y alcoba. En realidad se trataba de un acto social realizado en un espacio privado (...) $i$, quan la representació era estrictament privada, a les sales $i$ alcoves ${ }^{51}$.

48. CURET, F.: Teatres particulars... pp. 113-114.

49. AHCB. MS A 218. Calaix de Sastre XVIII (1 gener-30 juny) Fons Artís.

50. AHCB. D'Amat i de Cortada, R. Baró de Maldà.: Miscelllània XI. pp. 471-501.

51. FÀBREGAS, X.: Les formes de diversió... p. 73. 